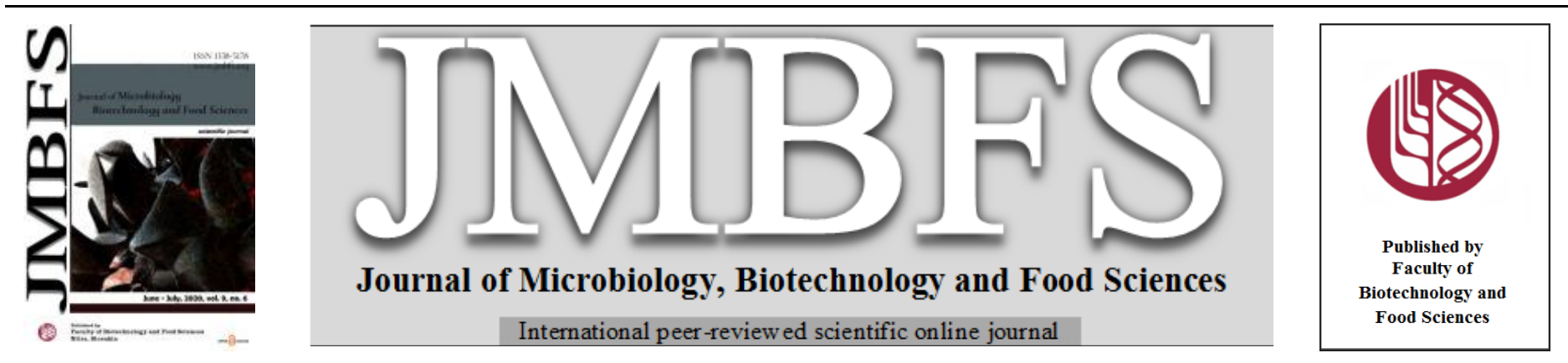

\title{
THE VIABILITY OF ENCAPSULATED Lactobacillus plantarum DURING CUPCAKE BAKING PROCESS, STORAGE, AND SIMULATED GASTRIC DIGESTION
}

\author{
Lieu My Dong *', Nguyen Thien Luan ${ }^{1}$, Dang Thi Kim Thuy ${ }^{2}$ \\ Address(es): \\ ${ }^{1}$ Faculty of Food Science and Technology, Ho Chi Minh City University of Food Industry, 140 Le Trong Tan, Tay Thanh Ward, Tan Phu District, Ho Chi Minh City, \\ Viet Nam, phone number: +84989961848 \\ ${ }^{2}$ Department of Plant Cell Technology, Institute of Tropical Biology, 9/621 Ha Noi highway, Ho Chi Minh City, Viet Nam.
}

*Corresponding author: lieudong289@gmail.com

doi: 10.15414/jmbfs.2020.9.6.1157-1161

ARTICLE INFO

Received 23. 4. 2019

Revised 5. 2. 2020

Accepted 12. 2. 2020

Published 1. 6. 2020

Regular article open $\partial_{\text {ACCESS }}$

\begin{abstract}
In this study, the Lactobacillus plantarum viability in the cupcake according to baking time was investigated for the first time. $L$. plantarum was microencapsulated by the emulsion method in $\kappa$-carrageenan mixed with skim milk (CS sample) or carrageenan coated by skim milk (CcS sample). The average size, and the $L$. plantarum viability during cupcake baking, cold storage and in the simulated intestinal fluid (SGF) were investigated. The result showed that the particle size was $165 \mu \mathrm{m}$ and $320 \mu \mathrm{m}$ for the CS and CcS samples respectively. In the cupcake baking process indicated that the $L$. plantarum viability in control samples was decreased $0.21 ; 0.66 ; 2.13$; and $5.33 \log \mathrm{CFU} / \mathrm{cake}$ after 2; 4; 8; and 12 min baking respectively as compared to the initial, whereas the decreasing of the $L$. plantarum viability was 0.22 to $0.34 ; 0.80$ to $0.90 ; 1.48$ to 1.50 ; and 3.58 to $3.80 \mathrm{log}$ CFU/cake in CS samples and CcS samples respectively. The $\mathrm{pH}$ value of the control samples was 6.8 to 6.5 which tended to be lower than the microencapsulated samples during 14 days of storage, though there was not a significant difference. Additionally, the L. plantarum viability in the control, CS and CcS samples was tended to increase slightly during storage. However, L. plantarum cells showed high sensitivity with the SGF medium. The longer the storage time, the more sensitive $L$. plantarum in SGF. The CcS sample showed significant higher protective efficacy in SGF than the CS samples. The same result was not observed in simulated intestinal fluid. In the sensory test, the difference between the cupcake with and without the addition of microcapsules was not significant.
\end{abstract}

Keywords: carrageenan, cupcake, baking process, microencapsulation, probiotic, skim milk

\section{INTRODUCTION}

The term probiotic is a relatively new word meaning "for life" and it is currently used to name bacteria associated with beneficial effects for humans and animals (FAO/WHO., 2002). Probiotic bacteria have been used both in pharmaceutical preparations and in food products (Muzzafar et al., 2018). However, the application probiotic in food products are limited and currently provided by dairy products such as yogurt (Adhikari et al., 2000), mayonnaise (Lieu et al., 2017), skim milk Maciel et al., (2014), cheese and so on, and have few studies on bakery products, a non - dairy products. Besides, dairy products also cause lactose - intolerant (Majzoobi et al., 2018). Moreover, the price of dairy products makes the consumers who live in third-world countries are limited in consumption. Thus, the bakery products which supplemented probiotic can be an alternative way to solve that problem. In previous studies, to increase the viability of probiotic, many authors mingling the probiotic with cream that complemented the bread after baking (Zanjani et al., 2012), others chose to apply the mixing cream in between biscuits (Muzzafar et al., 2018). That would keep probiotic out of the effect of the hash baking condition and maintain a numerous probiotic after supplementing. In the opposite view, the loading directly probiotic in the dough before baking will give more choices that can be chosen by the target consumer. However, the heat sensitivity of probiotic bacteria leading to the inactivation that occurs during baking decreased the viability of probiotic (Majzoobi et al., 2018; Arslan et al., 2018). Microencapsulation techniques are the method to help probiotic organisms against the disadvantaging effect of the outside environment (González - Forte et al., 2014; Lieu et al., 2017; Zhang et al., 2018; Muzzafa et al., 2018; Arslan et al., 2018). Encapsulation involves the incorporation of food ingredients, enzymes, cells or other material in a small capsule and encapsulated material can be protected from moisture, heat or extreme conditions, thus enhancing their stability and maintaining viability (Gibbs et al., 1999). The microencapsulation includes extrusion, emulsion or spray-drying techniques, and so on (Lieu et al., 2017; Zanjani et al., 2012). Spray - drying technique is widely utilized to encapsulated probiotics in food However, the spray - drying process is associated with high cell mortality resulting from simultaneous dehydration and thermal inactivation microorganisms (Malmo et al., 2013). Besides, the dimension of microencapsulation produced by the spray - drying process usually has micron size (Lieu et al., 2017) that decreasing the survival rate of probioticsupplemented in the bakery during baking. On the other hand, the extrusion method deliveries the bigger beads (above $1000 \mu \mathrm{m}$ ) that support the protection of probiotic cells effectively, but it will give more negative sensory. Whereas the emulsion technique would make smaller particles which ranges between 70 to $500 \mu \mathrm{m}$ (Zanjani et al., 2012), and these particles are bigger than spray - drying method (Lieu et al., 2017) but ensuring to reduce the effect of these particles on sensory properties and structures of food (Arslan et al., 2018; Zanjani et al., 2012). The wall materials such as $\kappa$-carrageenan, alginate, and chitosan are demonstrated improving probiotic microorganism against the harsh condition. $\kappa-$ carrageenan was utilized for encapsulating probiotic cells by emulsion technique and was demonstrated that can be employed in protection Bifidobacteria shelf life in yogurt by Adikari et al., (2000). And skim milk, the purification products made from milk, also use as a wall material to protect probiotic in the previous study of Maciel et al., (2014) and the first time to show their potential protection. To increase the effectiveness of protecting probiotic bacteria, the combination of wall material is getting more interest. Carrageenan-locust bean gum coated milk microspheres making by extrusion method showed a high protective effect on Lactobacillus bulgaricus viability in SGF (Simulated gastric fluid) medium (Shi et al., 2013). Similarly, carboxymethyl cellulose $/ \kappa-$ Carrageenan blends encapsulated Lactobacillus plantarum by extrusion method showed higher protective effect than free carboxymethyl cellulose in SGF medium. Although many studies have been carried out, the incorporation of carrageenan and skim milk, making by emulsion method and supplement to cupcake was poorly reported. Therefore, in the present study, carrageenan was used as the main wall material, and skim milk was used as incorporating or coating agents. Lactobacillus plantarum ATCC 8014 was microencapsulated by the emulsion method and supplemented in the cupcake product. The thermal influence during baking, the change in the survival rate of probiotic, $\mathrm{pH}$ changing during storage, 
and the resistance in simulated intestinal fluid after storage was also carried out in this study.

\section{MATERIAL AND METHODS}

\section{Microorganisms}

Lactobacillus plantarum ATCC 8014 was harvested from $100 \mathrm{ml}$ of a 24-h culture $\left(37^{\circ} \mathrm{C}\right)$ by centrifugation at $5000 \mathrm{rpm}$. The cells were then washed twice and resuspended in $10 \mathrm{ml}$ of sterile saline water and used in the microencapsulation process.

\section{Microencapsulation}

The microencapsulation method was made according to the method described by Adhikari et al., (2000) with slight modifies. Briefly, a $10 \mathrm{ml}$ cell suspension was added into $40 \mathrm{ml}$ of $2.5 \%(\mathrm{w} / \mathrm{v})$ carrageenan $(\mathrm{CcS}$ samples) or the mix of carrageenan $(2.5 \%)$ and skim milk $0.5 \%(\mathrm{w} / \mathrm{v})(\mathrm{CS}$ samples). Then, stirring and heating in a magnetic hot plate stirrer at $45 \div 48^{\circ} \mathrm{C}$. Vegetable oil $(100 \mathrm{ml}$, Crisco) and Tween $800.1 \%$ (v/v) was added into the Becher as an emulsifier. Stirring and dispersing for 15 minutes at $45^{\circ} \mathrm{C}$ to allow for emulsification and microencapsulation to occur. Then, added slowly $100 \mathrm{~mL}$ of $\mathrm{KCl} 0.1 \mathrm{M}$ solution to break the emulsion. The particles were collected (in case of CS samples) or incubated (in shaking incubator at $200 \mathrm{rpm}$ ) in skim milk $0.5 \%(\mathrm{v} / \mathrm{v}$ ) (in case of carrageenan coated by skim milk; $\mathrm{CcS}$ samples). The particles were used immediately in the next steps. Examined microencapsulation yield in the microcapsule preparation and calculated according to the following formula:

$$
\text { Microencapsulation yield(\%) }=\frac{\sum \log C F U_{\text {after encapsulation process }}}{\sum \log C F U_{\text {before encapsulation process }}} \times 100 \%
$$

\section{Particle size examination}

The particles added in $50 \mathrm{ml}$ of distilled water and vortexed. Then $20 \mathrm{ml}$ samples were taken and checked by HORIBA LA-size 920 machine.

Cupcake samples preparation and the survival of bacteria during baking and storage

Standard cupcake formulation was prepared with the addition of flour, sugar, softened butter and egg (1:1:1:0.5, (w/w/w/w)). Vanilla and baking powder were added at $0.5 \%(\mathrm{w} / \mathrm{v})$ of the cake mix, and the ingredients were mixed using a blender. The microcapsules $(4 \% \mathrm{w} / \mathrm{w})$ were mingled with the dough, and then the mix was spread 50 grams into the tin. Conduct baking at $200^{\circ} \mathrm{C}$ for 12 minutes The temperature of the surface and core of the cupcake was examined by FLUKE-62 MAX and TESTO 106 machines. Cupcake samples were cooled down and stored at $4^{\circ} \mathrm{C}$. Cupcake samples contain free cells used as control samples. The $\mathrm{pH}$ of cupcake samples and the survival rate of L. plantarum were determined after the baking process immediately and determined every 2 days until 14 days of storage at $4^{\circ} \mathrm{C}$

\section{pH examination}

The $\mathrm{pH}$ value of the cupcake was determined every 2 days until 14 days of storage at $4^{\circ} \mathrm{C}$ by using a $10 \%$ dispersion of samples in distilled water using a $\mathrm{pH}$ meter. The $\mathrm{pH}$ meter was calibrated by standard buffer solutions 4 and 7 .

\section{Enumeration of the free and microencapsulated bacteria}

The viability of microencapsulated $L$. plantarum in the cupcake was made according to the method described by Adhikari et al., (2000) with slight modifies. Briefly, 5 grams of the cupcake was resuspended in $45 \mathrm{ml}$ sterile buffer phosphate (pH: 7, 0.1 M). The capsules were disintegrated by homogenizing in a stomacher and incubating for $20 \mathrm{~min}$ at $42^{\circ} \mathrm{C}$ before making serial dilutions in $0.1 \%$ sterile peptone buffered water. The counts were determined by plating on MRS agar plates and incubating for $48 \mathrm{~h}$ at $37^{\circ} \mathrm{C}$. The cupcake containing free bacteria were treated similarly.

\section{Effects of simulated gastric fluid (SGF) and intestinal fluid (SIF) on $L$. plantarum after 04 and 10 days of storage}

5 grams of the cupcake after 04 days and 10 days of storage were incubated in 45 $\mathrm{ml}$ of Simulated gastric fluid (SGF) medium $(9 \mathrm{~g} / \mathrm{l} \mathrm{NaCl}+3 \mathrm{~g} / 1$ pepsin (Himedia) adjusted to $\mathrm{pH} 2.5$ with $5 \mathrm{~N} \mathrm{HCl}$ ), at $37^{\circ} \mathrm{C}$ and shaking speed $100 \mathrm{rpm}$ for 120 minutes. Similarly, 5 grams of cupcake were incubated in $45 \mathrm{ml}$ of (simulated intestinal fluid) SIF medium $(0.85 \% \mathrm{NaCl}, 0.3 \%$ bile salts, adjusted to $\mathrm{pH} 6.5$ with $5 \mathrm{~N} \mathrm{NaOH}$ ) at $37^{\circ} \mathrm{C}$ for 240 minutes. The viability of $L$. plantarum in the cupcake was immediately assayed by plating on MRS media.

\section{Sensory evaluation}

The "A, not A" test was conducted with the objective of determining if a significant difference existed between A (cupcake without containing microcapsules) and 'not $\mathrm{A}^{\prime}$ (cupcake containing microcapsules). A sensory evaluation was conducted by 30 assessors. Each assessor was familiarized with the sensory characteristics of the target sample ('A') from the cupcake without containing microcapsules and the nontarget sample ('not A') from the cupcake containing microcapsules, and then received one test sample and asked to identify it as the 'target' or 'not the target'.

\section{Statistical analysis}

The data were subjected to analysis of variance (ANOVA) using Statgraphics 15 followed by Tukey test to compare means, with a significance level of $5 \%$ when the significant difference between treatments was noted. The Chi-square test was used for sensory evaluation. All tests were performed in triplicate and the data expressed as means \pm standard deviation.

\section{RESULTS AND DISCUSSION}

Influence of microencapsulation ways on the particle size and microencapsulation yield

The effect of microencapsulation ways on the particle size and microencapsulation yield is shown in Table 1. The result showed that the average size of the CcS sample was $165 \mu \mathrm{m}$ that smaller $(p<0.05)$ than the CS sample $(320 \mu \mathrm{m})$. Similarly, the microencapsulation yield of L. plantarum in the CS sample was higher than the CcS sample, which was $93.50 \%$ and $89.25 \%$ respectively. In previous studies, the emulsion method produced with unequal particle size because of the influence of homogenized processing. The particle size of alginate - resistant starch particles made by the emulsion method ranges 70 to $500 \mu \mathrm{m}$ and average size was $280 \mu \mathrm{m}$ (Zanjani et al., 2012) that smaller than the extrusion method that has an average size of $530 \mu \mathrm{m}$ and particle size ranges $1.62 \mathrm{~mm}-1.89 \mathrm{~mm}$ (Krasaekoopt et al., 2004). Similarly, the result of Valero-Cases et al., (2015) showed that microencapsulated L. plantarum made from the emulsion method has a smaller size than the extrusion method significantly.

Table 1 The average size and microencapsulation yield $(\%)$ made by different microencapsulation ways.

\begin{tabular}{lcl}
\multicolumn{1}{c}{ Microencapsulation ways } & $\begin{array}{c}\text { Average } \\
\text { size }(\mu \mathrm{m})\end{array}$ & $\begin{array}{l}\text { microencapsulation } \\
\text { yield }(\%)\end{array}$ \\
\hline $\begin{array}{l}\text { The mix of carrageenan and skim } \\
\text { milk (CS samples) }\end{array}$ & $320^{\mathrm{a}}$ & $93.50 \pm 1.04^{\mathrm{a}}$ \\
\hline \begin{tabular}{l} 
The beads coated with skim milk \\
\hline
\end{tabular} & $165^{\mathrm{b}}$ & $89.25 \pm 0.78^{\mathrm{b}}$
\end{tabular}

(CcS samples)

ab Parameters with different superscript letters within the same column have significant differences $(p<0.05)$

The particle size is one of the important factors affecting food sensory properties. In the emulsion method, the particles are formed in micron size and deliver smooth texture when adding to food products (Zanjani $\boldsymbol{e t}$ al., 2012). However, the small size may not give enough protection to probiotic bacteria (Shi et al., 2013). The small particle size $(3 \mu \mathrm{m})$ did not show the protective effect of wall material on L. reuteri treating at $80^{\circ} \mathrm{C}$ in $5 \mathrm{~min}$ (Malmo et al., 2013). The present study showed that microencapsulation ways affected significantly the particle size and the microencapsulation yield (Table 1). This phenomenon could explain that the incubation phase with skim milk in the shaking machine $(200 \mathrm{rpm})$ that would make the particles separated that leading to decrease particle size as well as the microencapsulation yield.

\section{Impact of baking temperature on the viability of $L$. plantarum in the cupcake}

The temperature changes of bakery samples and the survival rate of L. plantarum were presented in Figure 1. Temperature values of surface and core of cupcake samples were different significantly $(p<0.05)$, they began from ambient temperature up to $108^{\circ} \mathrm{C}$ and $82^{\circ} \mathrm{C}$, respectively. The difference was $26^{\circ} \mathrm{C}$ after 12 min of baking at $200^{\circ} \mathrm{C}$. The heating treatment of the baking process affected significantly the survival rate of $L$. plantarum. The viability of $L$. plantarum was decreased $0.21 ; 0.66 ; 2.13$; and $5.33 \log$ CFU/cake after 2, 4, 8 and $12 \mathrm{~min}$ baking respectively as compared to the initial. After $12 \mathrm{~min}$ baking, the viable $L$. plantarum of free cells, CS, and $\mathrm{CcS}$ samples decreased dramatically from $10.18 \pm 0.18$ to $4.85 \pm 0.15 \log$ CFU/cake; $10.05 \pm 0.15$ to $6.25 \pm 0.16 \log$ CFU/cake; and $9.80 \pm 0.20$ to $6.22 \pm 0.18 \log \mathrm{CFU} /$ cake respectively. 


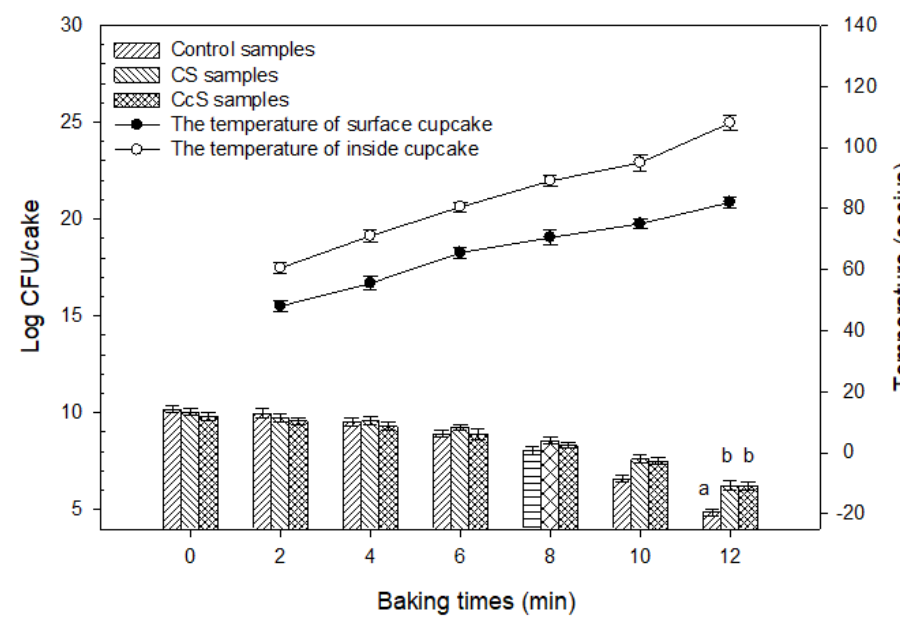

Figure 1 Impact of baking temperature on the viability of $L$. plantarum in the cupcake, ${ }^{a b}$ Parameters with different superscript letters have significant differences $(p<0.05)$

In the previous studies were shown that the probiotic bacteria inactivation appeared in thermal treatment upon two factors: temperature and humidity. Zhang et al., (2018) demonstrated that the thermal inactivation of L. plantarum presented during the baking process and was lost 4 to $5 \log \mathrm{CFU} / \mathrm{g}$ in their survival rate. Reid et al., (2007) shown that WPI - based microsphere protective solution with $L$. rhamonus in biscuit dropped of $3 \log$ after baking at $280^{\circ} \mathrm{C}$ in 5 min and storage for $24 \mathrm{~h}$. Malmo et al., (2013) showed that probiotic bacteria encapsulated by spray - drying method (average size about $3 \mu \mathrm{m}$ ) mere maintained $10 \%$ survival cells after 10 min baking time at $180^{\circ} \mathrm{C}$. However, in the previous studies, the influence of baking time on the probiotic viability in the cupcake was not reported. In the present study, the surface and core temperature of the cupcake were significantly different (Figure 1). The L. plantarum viability was decreased rapidly when the temperature inside the cupcake was up to $70.5^{\circ} \mathrm{C}$ after $8 \mathrm{~min}$ of baking (Figure 1). The results also indicated that microcapsules presented the protective role to $L$. plantarum cells was higher significantly than free cells and reached over $6 \log \mathrm{CFU} / \mathrm{cake}$ and achieved the requirement of probiotic-supplemented products. When the microcapsule was exposed to heat, the outer hydrophobic layer melted, and it absorbed heat during melting leading to the temperature of the microcapsule center, which contains the probiotics, could remain cooler than its surroundings (Arslan et al., 2018). These results suggested that the component of the wall material and the particle size play an important role in the probiotic's thermal resistance. In addition, the food matrix is a factor that improves the probiotic's thermal resistance. Malmo et al., (2013) shown that the heat resistance of $L$. reuteri DSM 17938 found in food was better than in vitro test, this phenomenon related to different food ingredients (carbohydrates and lipids) on the bacterial viability (during baking). Besides, the temperature of the center and surface of bread differ significantly in which the center temperature is cooler than the surface during bread baking (Zhang $\boldsymbol{e t}$ al., 2018). These help probiotic bacteria overcome the baking processing. However, the protective effect of carrageenan and skim milk on probiotic's therma resistance during baking processing was poorly reported. In the present study found that have a significant difference in microencapsulated probiotic and free cells (Figure 1). The results also indicated that the microencapsulation made from carrageenan and skim milk and the carrageenan beads coated with skim milk were not a significant difference $(p>0.05)$. These suggested that the hea tolerance of microencapsulated $L$. plantarum was not affected by microencapsulation ways.

\section{Effect of storage conditions on the survival of $L$. plantarum in the cupcake.}

The influence of storage condition on the $\mathrm{pH}$ change and the L. plantarum viability were shown in Figure 2. The results showed that the $\mathrm{pH}$ value of the experimental samples was not changed significantly during storage. The $\mathrm{pH}$ value of the control samples tended to be lower than the microencapsulated samples, however, there was not a significant difference. In the other hand, $L$ plantarum viability of the control, CS and CcS samples were not changed dramatically and tended to increase slightly from $4.85 \pm 0.15$ to $5.18 \pm 0.18 \mathrm{log}$ $\mathrm{CFU} / \mathrm{cake} ; 6.25 \pm 0.16$ to $6.35 \pm 0.20 \log \mathrm{CFU} / \mathrm{cake}$; and $6.22 \pm 0.18$ to $6.28 \pm$ $0.21 \log \mathrm{CFU} / \mathrm{cake}$ during 10 days of storage at $4^{\circ} \mathrm{C}$, respectively. The $L$ plantarum viability was decreased after 14 days of storage and more rapidly in the next two days, and remain $4.21 \pm 0.19 \log$ CFU/cake, $5.81 \pm 0.17 \log$ $\mathrm{CFU} /$ cake and $5.92 \pm 0.22 \log \mathrm{CFU} /$ cake for the control, $\mathrm{CS}$ and $\mathrm{CcS}$ samples respectively.

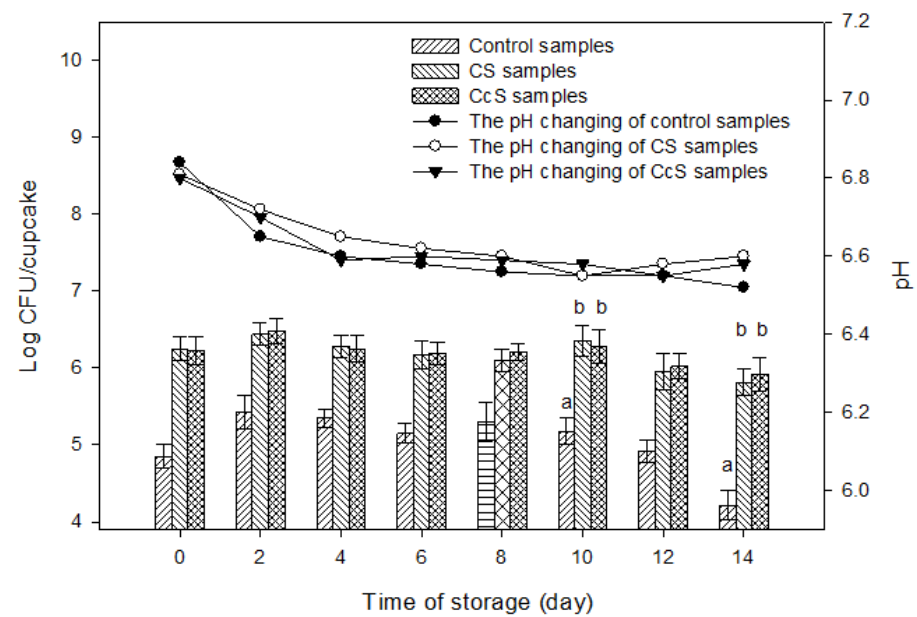

Figure 2 Effect of storage conditions on the L. plantarum viability in the cupcake ab Parameters with different superscript letters have significant differences $(p<0.05)$

The $\mathrm{pH}$ value change during the storage of products was reported in previous studies. Yogurt, mayonnaise, and many products which supplemented with probiotic were investigated that $\mathrm{pH}$ value decreased during storage at $4^{\circ} \mathrm{C}$ (Adhikari et al., 2000; Lieu et al., 2017). Many authors reported that the metabolic phenomenon existed towards generating more organic acid during storage and the decrease in $\mathrm{pH}$ value was a consequence. However, the probiotic bakery products are changed slightly in the $\mathrm{pH}$ value unlike dairy products (Figure 2). Zanjani et al., (2012) reported that the $\mathrm{pH}$ value of cream filling supplemented with L. casei ranged 6.5 to 5.88 and 6.5 to 6.38 in the free cell and encapsulated cell samples after four weeks of storage at $4^{\circ} \mathrm{C}$. Similarly, the $\mathrm{pH}$ value of cream-filled, marmalade -filled and chocolate-coated cake contained microcapsules probiotic was decreased slightly after 90 days of storage (Arslan et al., 2018). These results indicated that the metabolism of microencapsulated probiotic in the cupcake was very slow, which help cake sensory properties were unchanged during storage time.

The influence of storage condition on probiotic viability is received a lot of concern due to the lower probiotic viability during storage leading to decreasing of the benefit of health to the customer. In previous studies showed that the storage temperature affects significantly probiotic viability. In the storage process, probiotic bakery products were generally stored in room more temperate such as at $20^{\circ} \mathrm{C}$ in biscuit coated with methylcellulose (González - Fontez et al., 2014), $23^{\circ} \mathrm{C}$ in biscuit (Reid et al., 2007), $25^{\circ} \mathrm{C}$ in bread and in cream biscuit (Zhang et al., 2018; Muzzafar et al., 2018) all monitored that the probiotic viability decreased during storage time. On the contrary, Zanjani et al., (2012) demonstrated that probiotic viability in the cream cake was better at $4^{\circ} \mathrm{C}$ than at $25^{\circ} \mathrm{C}$. Arslan et al., (2018) reported that encapsulated probiotic which supplemented in cream-filled and chocolate-coated decreased dramatically after 30 days of storage at $4^{\circ} \mathrm{C}$. Zanjani et al., (2012) reported that the L. acidophilus viability in cream - filled in a baked cake was lost $8.09 \mathrm{log}$ CFU/g after four weeks of storage. However, in the present study, it is interesting to note that the viability of $L$. plantarum did not decrease during storage (Figure 2). This result agrees with Majzoobi et al., (2018) who indicated that the frozen storage process did not affect significantly the probiotic viability in re-baked bread after four weeks of storage at $-20^{\circ} \mathrm{C}$. This phenomenon can explain that the probiotic survival was affected by temperature degrees and the kind of compound of the bakery. Moreover, previous studies suggested that a suitable wall matrix in food could deliver probiotic protection better than others (Gibbs et al., 1999; Adikari et al., 2000; Krasaekoopt et al., 2004; Malmo et al., 2013). Zanjani et al., (2012) reported that the viability of $L$. casei that encapsulated in alginate - starch wall matrix was significantly improved which lost just 1 log after one week of storage at $4^{\circ} \mathrm{C}$. In the present study indicated that the $L$. plantarum viability in the samples containing unencapsulated and encapsulated cells was no significan difference during storage (Figure 2). It could be explained that the food matrix and storage condition $\left(4^{\circ} \mathrm{C}\right)$ is not becoming a proper media culture for probiotic growth. In this condition, probiotic cells returned into the anabiosis phase that leading to the metabolic activity of $L$. plantarum was slow down, and it is suitable for maintaining the probiotic viability during 10 days of storage However, in the next days of storage, the viability of $L$. plantarum trended to decrease faster and below the minimum value requirement in probiotic products ( $<6 \log$ CFU/cake) after 14 days of storage. These indicated that cold storage condition starts inhibiting the generation of L. plantarum and decreasing their survival rate. Therefore, 10 days storage was necessary for ensuring that the counts of microencapsulated $L$. plantarum were maintained in the cupcake, suitably (Figure 2). 


\section{Effect of SGF and SIF medium on the viability of $L$ plantarum in the} cupcake after 04 and 10 days of storage

The effect of SGF and SIF conditions on the survival rate of L. plantarum in the cupcake after 04 and 10 days of storage were shown in Table 2 . The result showed a difference significantly $(p<0.05)$ in the free and microencapsulated cells. In SGF condition, after 4 and 10 days of storage, the survival rate of $L$. plantarum in control samples was not recorded while the L. plantarum viability in the CS samples was $3.42 \pm 0.15 \log$ CFU/cake and 2.65 $\pm 0.15 \log$ CFU/cake, in
$\mathrm{CcS}$ samples was $4.39 \pm 0.17 \log \mathrm{CFU} /$ cake and $3.59 \pm 0.17 \log \mathrm{CFU} / \mathrm{cake}$ respectively. In SIF condition, the survival rate of $L$. plantarum in control samples after 4 and 10 days of storage was reached $4.05 \pm 0.16 \log \mathrm{CFU} / \mathrm{cake}$ and $3.85 \pm 0.11 \log \mathrm{CFU} / \mathrm{cake}$ which lower $(p<0.05)$ significantly than $\mathrm{CS}$ and $\mathrm{CcS}$ samples, and there was no significant difference $(p>0.05)$ between CS and CcS samples. The results showed that the storage time affected significantly on the $L$. plantarum sensibility with the SGF medium (Table 2).

Table 2 The survival rate of L. plantarum in SGF and SIF after the 04th and 10th days of storage.

\begin{tabular}{|c|c|c|c|c|c|c|}
\hline \multirow{2}{*}{$\begin{array}{l}\text { Cupcake } \\
\text { samples }\end{array}$} & \multicolumn{3}{|c|}{ 04th day of storage (log CFU/cake) } & \multicolumn{3}{|c|}{ 10th day of storage (log CFU/cake) } \\
\hline & Initial & After 2h in SGF & After $4 \mathrm{~h}$ in SIF & Initial & After 2h in SGF & After $4 h$ in SIF \\
\hline Control & $5.35 \pm 0.12^{\mathrm{Aa}}$ & $0^{\mathrm{Aa}}$ & $4.05 \pm 0.16^{\mathrm{Aa}}$ & $5.18 \pm 018^{\mathrm{Aa}}$ & $0^{\mathrm{Aa}}$ & $3.85 \pm 0.11^{\mathrm{Aa}}$ \\
\hline CS & $6.28 \pm 0.15^{\mathrm{Ab}}$ & $3.42 \pm 0.15^{\mathrm{Ab}}$ & $5.43 \pm 0.22^{\mathrm{Ab}}$ & $6.35 \pm 0.20^{\mathrm{Ab}}$ & $2.65 \pm 0.15^{\mathrm{Bb}}$ & $5.05 \pm 0.20^{\mathrm{Ab}}$ \\
\hline CcS & $6.25 \pm 0.17^{\mathrm{Ab}}$ & $4.39 \pm 0.17^{\mathrm{Ac}}$ & $5.55 \pm 0.20^{\mathrm{Ab}}$ & $6.28 \pm 0.21^{\mathrm{Ab}}$ & $3.59 \pm 0.17^{\mathrm{Bc}}$ & $5.28 \pm 0.19^{\mathrm{Ab}}$ \\
\hline
\end{tabular}

${ }^{\mathrm{AB}}$ Parameters with different superscript letters within the same row (the same condition) have significant differences $(p<0.05)$

${ }^{\text {abc }}$ Parameters with different superscript letters within the same column have significant differences $(p<0.05)$

The survival rate of probiotic bacteria in SGF and SIF media plays an important role in providing healthy benefice for their host. Evaluating the survival rate of probiotic bacteria in SGF and SIF media was usually carried out in previous studies. The SGF medium has a low $\mathrm{pH}$ value is an acidic medium that excites large of $\mathrm{H}^{+}$ion which is an inhibited factor on microorganisms. Zhu et al., (2006) reported that the digestion enzyme (pepsin) in low $\mathrm{pH}$ medium that increasing the antibacterial effect against $E$. coli because of their protein hydrolyzed ability, and $E$. coli resistance related with $\mathrm{pH}$ value and enzymatic concentration. On the other hand, bile salt condition also affects probiotic survival. Bile salt impact the bacterial cell membrane, decreases intracellular $\mathrm{pH}$ value, causes plasmolysis, and positive gram microbial cells are more sensitive than a negative gram (Begley et al., 2005). In other studies, showed that L. plantarum cells were sensitive in low $\mathrm{pH}$ with the lost cells were $6.61 \mathrm{log}$ CFU/g (Ding et al., 2007) or could be up to $10 \log$ CFU/g (Dafe et al., 2017). Those studies also have shown that the survival rate of encapsulated probiotic was higher than free cells that incubated in SGF and SIF media because of the wall material of microcapsules displayed as a barrier against the diffusion (Shi et al., 2007; Lieu et al., 2017) Moreover, the incorporation of every single wall material increases the protective effect more significantly than the individual wall material. The incorporation of $k$ - carrageenan and whey protein that increased significantly in the survival rate of L. plantarum in SGF, was reported by Hernández-Rodríguez et al., (2014) Similarly, Maciel et al., (2014) indicated that the viability of probiotic encapsulated by skim milk was not affected when incubating in the SGF medium ( $\mathrm{pH} 2$ ). This phenomenon can be explained that skim milk maintained $\mathrm{pH}$ value inner capsules higher than $\mathrm{pH}$ value outside leading to improved significantly in the survival rate of encapsulated probiotic (Heideback $\boldsymbol{e t}$ al., 2009). The present study showed that the microencapsulation process affected significantly on the $L$. plantarum viability in which the particles coated by skim milk (CcS samples) delivered a higher survival rate than the particles (CS samples) made by the mix of carrageenan and skim milk (Table 2). These results could be explained that, in CS samples, skim milk interfered in the cross-linking formatting processing leading to the $\mathrm{H}^{+}$ion diffuse through the particle structure and destroyed probiotic cells. In $\mathrm{CcS}$ samples, carrageenan particles were incubated in skim milk which not only would not affect the cross-linking matrix of particles but also reduce their porous. Finally, it helped to increase the survival rate of $L$ plantarum cells in the low $\mathrm{pH}$ environment (Table 2). The influence of the cold storage condition on the probiotic viability in SGF and SIF conditions were reported in previous studies. Cristina et al., (2002) indicated that the sensitive degrees of the fresh and cold storing $L$. johnsonii La1 cells with SGF medium were not significantly different, but in the SIF medium, the fresh $L$. johnsonii La1 cells reached a higher survival rate than the cold storage cells. However, in the present study showed that storage condition affected the L. plantarum sensitivity in SGF and SIF conditions (Table 2). This result was similar to Priscilla et al., (2015) who reported that Bifidobacterium animalis in ice cream after 120 days storage was more sensitive $(p<0,05)$ with SGF medium than after 30 days storage. Similarly, Dong et al., (2017) indicated that the longer the storage time, the more sensitive probiotic in SGF and SIF conditions. In the present study showed that the sensible degrees of $L$. plantarum with SGF medium increased during cold storage. However, the same result was not observed in the SIF medium (Table 2).

\section{Sensory evaluation}

The sensory evaluation of comparison of the cupcake with and without the addition of microcapsules $(4 \% \mathrm{w} / \mathrm{w})$, with the Chi-square value, was 0.144 (Statistical differences are found when the chi-square values are $\geq 3.8$ ) indicated that the difference between these samples was not significant $(p>0.05)$. The sensory evaluation is an important role that ensures the addition of the microcapsules to the cupcake would not affect the original cupcake sensory property. The sensory difference due to the supplementation of microcapsules could lead to consumer rejection.
Table 3 Comparison of cupcake with and without the addition of microcapsules showed that the Chi-square was 0.144 . Statistical differences are found when the Chi-square values are $\geq 3.8$.

\begin{tabular}{llll}
\hline \multirow{2}{*}{ Subjects responded } & \multicolumn{2}{c}{ Subjects received } & \multirow{2}{*}{ Total } \\
\cline { 2 - 3 } & $\mathbf{A}$ & Not $\mathbf{A}$ & \\
\hline $\mathbf{A}$ & 5 & 6 & 11 \\
\hline Not A & 10 & 9 & 9 \\
\hline Total & 15 & 15 & 30 \\
\hline
\end{tabular}

In previous studies, the microencapsulated Bifidobacterium longum B6 supplement into yogurt showed the difference with the non-microencapsulated sample (Adhikari et al., 2003). However, the research of Zanjani et al., 2012 showed that the body and texture of the cream-filled cake samples did not show a significant difference $(p>0.05)$ between the cream-filled cake containing free bacteria and encapsulated bacteria (average size was $280 \mu \mathrm{m}$ ). The same result was recorded in the present study (Table 3). There was no significant difference in cupcakes with and without the addition of microcapsules (Table 3). The significant difference was found in the cupcake adding more than $5 \%$ w/w of microcapsules (data not shown). The result suggested that the amount of the microcapsules, as well as the particle size, affect the sensory properties of the cupcake.

\section{CONCLUSION}

The present study showed that that the average particle size of the CcS sample was $165 \mu \mathrm{m}$ that smaller $(p<0.05)$ than the CS sample $(320 \mu \mathrm{m})$. Similarly, the microencapsulation yield of L. plantarum in the CS sample was higher than the $\mathrm{CcS}$ sample. The baking temperature impacted significantly on the survival rate of $L$. plantarum, whereas refrigeration storage did not affect the $L$. plantarum viability. Microencapsulation technique improved the survival rate of $L$. plantarum during baking processing, storage, and exposed in simulated gastric digestion, specific the skim milk coated beads provided more protective than the mixed form. The survival rate of $L$. plantarum after baking was decreased dramatically $4.85 \log \mathrm{CFU} /$ cake from $10.18 \mathrm{log}$ CFU/cake initially, whereas the L. plantarum viability in microencapsulated samples reached over 6 log CFU/cake. The results also indicated that the L. plantarum counts in all experimental samples were not impacted by storage conditions at $4^{\circ} \mathrm{C}$. However, L. plantarum cells showed high sensitivity with the SGF and SIF media. The longer the storage time, the more sensitive probiotic in the SGF medium. In the 4 th and 10th days of storage, the L. plantarum viability in the control samples was not recorded after $2 \mathrm{~h}$ in the SGF medium and only remained $4.05 \mathrm{log}$ $\mathrm{CFU} /$ cake and $3.85 \mathrm{log} \mathrm{CFU} /$ cake after $4 \mathrm{~h}$ incubated in SIF that was lower than microencapsulated cell samples. The samples containing carrageenan particles coated by skim milk (CcS samples) showed significant higher protective efficacy in SGF medium than the mixed carrageenan and skim milk (CS samples). However, there was no significant difference between coating samples and mixed samples in the SIF medium after $4 \mathrm{~h}$ incubation. $\kappa$-carrageenan particles coating by skim milk not only did not affect the gel structure matrix but also limited the diffusion of $\mathrm{H}^{+}$into the microcapsule structure leading to enhance the survival rate of L. plantarum in SGF condition. Additionally, the difference between these samples was not significant in the sensory test. The result showed that the potential application of the microencapsulated probiotic bacteria supplementing directly in the dough before baking that diversify probiotic bakery products, but it also maintained necessary probiotic survival.

\section{REFERENCES}

Adhikari, K., A. Mustapha, I. U. Grün, and L. Fernando. (2000) Viability of Microencapsulated Bifidobacteria in Set Yogurt During Refrigerated Storage Journal of dairy science 83, no. 9: 1946-1951. https://doi.org/10.3168/jds.S0022$\underline{0302(00) 75070-3}$ 
Adikhari, K., Mustapha, A. \& Grun, I.U. 2003 Survival and metabolic activity of microencapsulated Bifidobacterium in stirred yoghurt. Journal of Food Science 68, p275-280. https://doi.org/10.1111/j.1365-2621.2003.tb14152.x

Arslan-Tontul S, Erbas M, Gorgulu A. (2018). The use of probiotic-loaded single and double layered microcapsules in cake production. Probiotic and Antimicrobial Protein. https://doi.org/10.1007/s12602-018-9467-y

Begley M, Gahan CGM, Hill C (2005) The interaction between bacteria and bile FEMS Microbiol Rev 29(4):625-651. https://doi.org/10.1016/j.femsre.2004.09.003

Cristina A, Roberto F, Margherita R, Carlo P, Lorena S. (2002). Survival of Lactobacillus johnsonii La1 and influence of its addition in retail-manufactured ice cream produced with different sugar and fat concentrations. Int Dairy J 12 (23):201-208. https://doi.org/10.1016/S0958-6946(01)00159-5

Dafe A, EtemadiaH , Zarredarb H , Mahdavinia GR (2017) Development of novel carboxymethyl cellulose/k-carrageenan blends as an enteric delivery vehicle for probiotic bacteria. International Journal of Biological Macromolecules 97:299-307. https://doi.org/10.1016/j.ijbiomac.2017.01.016

Ding, W. K., \& Shah, N. P. (2007) Acid, bile, and heat tolerance of free and microencapsulated probiotic bacteria. J Food Sci 72(9):446-450. https://doi.org/10.1111/j.1750-3841.2007.00565.x

Dong, Lieu My, Thuy, Dang Thi Kim, and Nguyen Thuy Huong. (2017) The influence of homogenization and storage time on the viability of Lactobacillus casei and Bifidobacterium bifidum in ice cream. Science and Technology $\begin{array}{lllll}\text { Development Journal } 20, & \text { no. }\end{array}$ https://doi.org/10.32508/stdj.v20iK1.416

FAO/WHO. (2002) Health and nutritional properties of probiotics in food including powder milk with live lactic acid bacteria. Report of a Joint FAO/WHO Expert Consultation. Cordoba, Argentina.

Gibbs BF, Kermasha S, Alli I, Mulligan CN (1999) Encapsulation in the food industry: a review. Int J Food Sci Nutr 50(3):213-224. https://doi.org/10.1080/096374899101256

González-Forte L, Bruno E, Martino M. (2014) Application of coated on dog biscuits for extended survival of probiotic bacteria. Animal Feed Sci \& Tech 195:76-84. https://doi.org/10.1016/j.anifeedsci.2014.05.015

Heidebach T, Forst P, Kulozik U (2009) Microencapsulation of probiotic cells by means of rennet-gelation of milk proteins. Food Hydrocoll 23(7):1670-1677. https://doi.org/10.1016/j.foodhyd.2009.01.006

Hernández-Rodríguez L, Lobato-Calleros C Pimentel-González DJ , VernonCarter EJ. (2014) Lactobacillus plantarum protection by entrapment in whey protein isolate: k-carrageenan complex coacervates. Food Hydrocoll 36:181-188. https://doi.org/10.1016/j.foodhyd.2013.09.018

Krasaekoopt, W., Bhandari, B., \& Deeth, H. (2004) The influence of coated materials on some properties of alginate beads and survivability of microencapsulated probiotic bacteria. Int Dairy J 14(8):737-743. https://doi.org/10.1016/j.idairyj.2004.01.004

Lieu, M. D., Dang, T. K. T., \& Nguyen, T. H. (2017). Viability of microencapsulated Lactobacillus casei in synbiotic mayonnaise. Food Research, 1(6), 234-239. https://doi.org/10.26656/fr.2017.6.103

Maciel GM,K.S.Chaves, C.R.F.Grosso, M.L.Gigante (2014) Microencapsulation of Lactobacillus acidophilus La-5 by spray-drying using sweet whey and skim milk as encapsulating materials. J Dairy Sci 97(4): 1991-1998. https://doi.org/10.3168/jds.2013-7463

Majzoobi M, Aghdam MBK, Eskandari MH, Farahnaky A. (2018) Quality and microbial properties of symbiotic bread produced by straight dough and frozen part-baking methods. J Texture Stud 2019:1-7. https://doi.org/10.1111/jtxs.12386 Malmo C, La Storia A, Mauriello G (2013) Microencapsulation of Lactobacillus reuteri DSM 17938 cells coated in alginate beads with chitosan by spray drying to use as a probiotic cell in a chocolate souffle. Food Bioprocess Technol 6(3):795-805. https://doi.org/10.1007/s11947-011-0755-8

Muzzafar A, Sharma V (2018). Microencapsulation of probiotic for incorporation in cream biscuit. Journal of Food Measurement and Characterization. https://doi.org/10.1007/s11694-018-9835-z

Priscilla DLS, Maria de FB, Karina MOS, Roberta TPC (2015) Potentially probiotic ice cream from goat's milk: Characterization and cell viability during processing, storage and simulated gastrointestinal conditions. LWT - Food Sci Technol 62(1):452-457. https://doi.org/10.1016/j.lwt.2014.02.055

Reid AA, Champagne CP, Gardner N, Fustier P, Vuillemard JC (2007) Survival in food systems of Lactobacillus rhamnosus R011 microentrapped in whey protein gel particles. J Food Sci 72(1): 31-37. https://doi.org/10.1111/j.17503841.2006.00222.x

Shi. L. E, Z.H. Li, Z.L. Zhan (2013) Encapsulation of Lactobacillus bulgaricus in carrageenan-locust bean gum coated milk microspheres with double layer structure. $\quad$ LWT-Food $\quad$ Sci $\quad$ Technol 54(1):147-151. https://doi.org/10.1016/j.lwt.2013.05.027

Valero-Cases E., Frutos M. J (2015) Effect of different types of encapsulation on the survival of Lactobacillus plantarum during storage with inulin and in vitro digestion. LWT-Food science and technology 64(2): 824-828 https://doi.org/10.1016/j.lwt.2015.06.049

Zanjani MAK, Tarzi BG, Sharifan A, Mohammadi N, Bakhoda H, Madanipour MM (2012) Microencapsulation of Lactobacillus casei with calcium alginate- resistant starch and evaluation of survival and sensory properties in cream-filled cake. Afr J Microbiol Res 6(26):5511-5517. https://doi.org/10.5897/ajmr12.972 Zhu H, Hart CA, Sales D, Roberts NB (2006) Bacterial killing in gastric juice effect of $\mathrm{pH}$ and pepsin on Escherichia coli and Helicobacter pylori, Journal of Medical Microbiology 55 1265-1270. https://dx.doi.org/10.1099/jmm.0.46611-0 Zhang, L., Taal, M. A., Boom, R. M., Chen, X. D., \& Schutyser, M. A. (2018) Effect of baking conditions and storage on the viability of Lactobacillus plantarum supplement to bread. Food Sci Technol 87: 318-325. https://doi.org/10.1016/j.lwt.2017.09.005 